\title{
Construction and test of forecasting push-pull demand model of urban
}

\author{
emergency supplies \\ Xiaowei Han ${ }^{\mathrm{a}^{*}}$, Gaofeng Yue ${ }^{\mathrm{b}}$, Fachang $\mathrm{Li}^{\mathrm{a}}$, Xiaoliang Song ${ }^{\mathrm{b}}$ \\ ${ }^{a}$ School of information engineering, Shenyang University, China \\ ${ }^{\mathrm{b}}$ School of information engineering, Shenyang University, China \\ *Corresponding author: Gaofeng Yue,student,13840149880,643375731@qq.com
}

\begin{abstract}
The research of demand forecast of city emergency supplies is of great significance to the management of urban emergency logistics. Taking the city public health emergency as the background, the paper will establish a model of push - pull demand forecasting about solving the problem of emergency supplies which is efficient and economical in emergency supplies efficiency under an emergency situation. The grey prediction method is used to solve the model by using the example analysis. The result shows the feasibility of the model and algorithm.
\end{abstract}

Key words: emergency logistics; supplies demand; push - pull type; gray prediction algorithm

\section{Introduction}

The emergency logistics for city is a kind relying on the city emergency system ${ }^{1}$. The materials demand forecast is the bridge of emergency logistics. It is not only related to allocate effectively and meet the demand for emergency supplies in the disaster area, but also determines whether disaster losses can be minimized.

Fernando Ordonez, et al. according to the fairness and the demand of nodes, aimed to minimize the discontent of the people, and establishes the model by using the tabu search method ${ }^{2}$. Hongbo Qiao, et al (2009) ${ }^{3}$ proposed a modified method about classification for the status quo of emergency material classification, and constructed a demand calculation model of emergency material reserve point based on demand satisfaction rate. Xiao Wang and Yaming Zhuang(2011) ${ }^{4}$ proposed a prediction method including fuzzy set theory, neural network Hebb learning rule and multiple linear regression and case-based reasoning method. The problem of emergency material demand forecasting is a dynamic periodic decision process. 
The rescue mission is the first after the occurrence. But how to calculate the appropriate number of emergency supplies is a demand point, which requires the emergency center to do demand forecast work. This paper is based on the continuity of emergency events, grasping incremental of the information, considering the establishment a mode of push-pull demand forecast and achieving the utility of urban emergency material optimization.

\section{Model introductions}

\subsection{Problem description}

After the outbreak of public health emergencies, the emergency center continuously needs to improve degree of the dynamic development of emergency, increase the accuracy of information and demand forecast. The faced decision-making problem is: how to make a reasonable and effective forecast of the emergency materials to realize the maximization of the utility and to deal with the sudden events better.

\subsection{Symbol description}

$\mathrm{n}_{1}$ indicates that demand forecast is in the push stage; $\mathrm{n}_{2}$ indicates that demand forecast is in the pull stage. $\mathrm{X}_{1 \mathrm{i}}$ indicates the $\mathrm{i}$ influencing factors that affect the demand of materials in the stage of push, $\mathrm{P}_{1 \mathrm{i}}$ indicates the probability of occurrence of the $\mathrm{i}$ factor, $\mathrm{Q}_{1 \mathrm{i}}$ represents the demand for $\mathrm{i}$ factor of affecting requirements in the push, $\mathrm{X}_{2 \mathrm{j}}$ indicates the $\mathrm{j}$ influencing factor of affecting the demand in the pull-type stage, $\mathrm{P}_{2 \mathrm{j}}$ represents the probability of occurrence of $\mathrm{j}$ factor, $\mathrm{Q}_{2 \mathrm{j}}$ represents the demand for $\mathrm{j}$ factors of each affecting requirements in the pull. $\mathrm{S}_{1}$ represents urban emergency supplies in the push, $\mathrm{S}_{2 \mathrm{k}}$ represents the demand in the k stages in the pull, $S_{2(k+1)}$ represents the supplies demand in the pull forecast, $S$ is the total forecast demand.

\subsection{Model establishment}

Establish a total objective function $\operatorname{Max} S=S_{1}^{*}+S_{2(K+1)}^{*}$

The first step: using the experience of $n$ experts to predict the probability, calculating the value of each expert and taking the average as the first forecast value;(Value $n=5$ )

$$
\begin{gathered}
S_{1 \mathrm{i}}=\sum_{i=1}^{n} Q_{1 i} * P_{1 i} \\
\mathrm{~S}_{1}^{*}=\frac{1}{n} \sum_{i=1}^{n} S_{1 i}
\end{gathered}
$$


The second step, the use of gray correlation method structures pull model: (Value $n=5$ )

$$
X^{0}(k)=S_{2 k}=\sum_{j=1}^{n} Q_{2 j} * P_{2 j}
$$

therefore,take $k=1,2,3,4,5$. So, the utilize of gray prediction to take the original sequence as

$$
X^{(0)}=\left(X^{0}(1), X^{0}(2), X^{0}(3), X^{0}(4), X^{0}(5)\right)
$$

The cumulative production sequence.

$$
X^{(1)}=\left(X^{1}(1), X^{1}(2), X^{1}(3), X^{1}(4), X^{1}(5)\right)
$$

Based on gray predictions ,it can generate differential equation:

$$
\frac{d^{(1)} x}{d j}+\eta x^{(1)}=h
$$

$\eta$ and $\mathrm{h}$ are parameters to be estimated.According to the theory of gray relational prediction,

$$
\text { hypothesis: } H=\left(\begin{array}{l}
\eta \\
h
\end{array}\right), \quad B=\left[\begin{array}{c}
-\frac{1}{2}\left[X^{1}(2)+X^{1}(1)\right], 1 \\
-\frac{1}{2}\left[X^{1}(3)+X^{1}(2)\right], 1 \\
-\frac{1}{2}\left[X^{1}(3)+X^{1}(4)\right], 1 \\
\left.-\frac{1}{2}\left[X^{1}(4)+X^{1}(5)\right], 1\right] \\
y=\left(X^{0}(2), X^{0}(3), X^{0}(4), X^{0}(5)\right)^{T}
\end{array}\right.
$$

In equation (9), T represents transpose. Using of matrix knowledge, giving $M=\left(B^{T} B\right)^{-1}$, by the least squares method $H=\left(B^{T} B\right)^{-1} B^{T} y$. Thus, the solution of formula (2.7) is obtained: (k $=1,2,3,4,5)$

$$
X^{1}(k+1)=\left[X^{(0)}-\frac{h}{\eta}\right] e^{-k \eta}+\frac{h}{\eta}
$$

Then, the degradation process is performed:

$$
\left.\mathrm{S}_{2(k+1)}^{*}=X^{0}(B+1)=X^{1}\right) k+1-X^{1} k
$$

The residual test is carried out firstly, and the residual value is calculated: $(k=1,2,3,4,5)$

$$
e(k)=x^{0}(k)-x_{*}^{0}(k)
$$

And calculate the error mean:

$$
\omega=\frac{1}{n} \sum_{k=1}^{n} e(k)
$$

Select the reference sequence:

$$
X_{0}=\left\{X_{0}(k) \mid k=1,2,3,4,5\right\}=\left(X_{0}(1), X_{0}(2), X_{0}(3), X_{0}(4), X_{0}(5)\right)
$$

Where: $\mathrm{k}$ is the time. 
Assuming there are m comparison sequences, there are:

$$
X_{1}=\left\{X_{1}(k) \mid k=1,2,3,4,5\right\}=\left(X_{1}(1), X_{1}(2), X_{1}(3), X_{1}(4), X_{1}(5)\right)
$$

We said: $\quad \xi(k)=\frac{\min \min \left|X_{0}(k)-X_{1}(k)\right|+p \max \max \left|X_{0}(k)-X_{1}(k)\right|}{\left|X_{0}(k)-X_{1}(k)\right|+p \max \max \left|X_{0}(k)-X_{1}(k)\right|}$

It is the correlation coefficient of the comparison sequence $\mathrm{X}_{1}$ to the reference sequence $\mathrm{X}_{0}$ at time $\mathrm{k}$. Among , $p \in[0,1]$ is the resolution ratio,frequently value: $\mathrm{p}=0.5$, and calling $\min \min \left|X_{0}(k)-X_{1}(k)\right|$ and $\max \max \left|X_{0}(k)-X_{1}(k)\right|$ are the middle, the two minimum residual and the two maximum residual. $(\mathrm{k}=1,2,3,4,5)$.

Often said:

$$
r_{1}=\frac{1}{n} \sum_{k=1}^{n} \xi_{1}(k)
$$

is the correlation degree of $\mathrm{X}_{1}$ to $\mathrm{X}_{0}$ at $\mathrm{k}$ time. We often think that $\mathrm{p}=0.5, \mathrm{r}_{1} \geq 0.6$ is the correlation degree to meet the judgment basis.

The third step is the variance ratio test, the formula is as follows:

Prediction deviation means and raw data mean:

$$
\bar{e}=\frac{1}{n} \sum_{k=1}^{n} e(k), \bar{X}^{0}=\frac{1}{n} \sum_{k=1}^{n} X^{0}(k)
$$

Raw data standard deviation: $\quad S_{1}=\sqrt{\frac{1}{n} \sum_{k=1}^{n}\left(X^{0}(k)-\bar{X}^{0}\right)^{2}}$

Standard deviation of prediction error: $\quad S_{2}=\sqrt{\frac{1}{n-1} \sum_{k=1}^{n}(e(k)-\bar{e})^{2}}$

Variance ratio:

$$
C=\frac{S_{2}}{S_{1}}, \mathrm{~S}_{0}=0.6745 \mathrm{~S}_{1}
$$

In the deviation, residuals and variance ratio are the smaller, but the prediction accuracy is the better. Shown in table1. Among them, the fourth level is the prediction failure grade.

Table 1- Model precision grade

\begin{tabular}{cllll}
\hline Precision grade & Class A & Class B & Class C & Class D \\
\hline $\mathrm{C}$ & $<0.35$ & $<0.5$ & $<0.65$ & $\geq 0.65$ \\
\hline
\end{tabular}




\section{Example analyses}

A city in a sudden outbreak of cholera epidemic, the experts predict that the event grade is the second, and given a sheet about the affecting factors, which is shown in table 2 . At the same time in five factors, the need for each factor to occur completely is $(50,60,55,65,70)$. It is necessary to forecast the demand for first types of materials of emergency materials.

To forecast the city emergency materials under the emergency condition.

Push prediction will be analyzed, can be solved:

$$
\begin{gathered}
S_{1 \mathrm{i}}=\sum_{i=1}^{n} Q_{1 i} * P_{1 i} \\
S_{1 \mathrm{i}}=\frac{1}{n} \sum_{i=1}^{n} S_{1 i}
\end{gathered}
$$

Substitute data from table 2.2 ,so $\mathrm{S}_{1}{ }_{1}=59.9$ box, about 60 box.

Table 2-The demand for emergency supplies factors influencing the probability table in the peak period emergency

\begin{tabular}{|c|c|c|c|c|c|}
\hline factors & & & & \\
probability & 1 & 2 & 3 & 4 & 5 \\
\hline 1 & 0.2 & 0.2 & 0.3 & 0.25 & 0.05 \\
\hline 2 & 0.1 & 0.2 & 0.35 & 0.15 & 0.2 \\
\hline 3 & 0.1 & 0.25 & 0.25 & 0.2 & 0.2 \\
\hline 4 & 0.2 & 0.25 & 0.05 & 0.2 & 0.3 \\
\hline 5 & 0.4 & 0.15 & 0.05 & 0.2 & 0.2 \\
\hline
\end{tabular}

Using formula (4) obtained initial demand sequence $(68,72,74,78,80)$, there is a gray prediction model:

$$
x^{(0)}=\left(x^{0}(1), x^{0}(2), x^{0}(3), x^{0}(4), x^{0}(5)\right)=(68,72,74,78,80)
$$

Then obtain: $\quad x^{(1)}=\left(x^{0}(1), x^{0}(2), x^{0}(3), x^{0}(4), x^{0}(5)\right)=(68,140,214,292,372)$

SO : 


$$
\begin{aligned}
& B=\left[\begin{array}{c}
-\frac{1}{2}\left[X^{1}(2)+X^{1}(1)\right], 1 \\
-\frac{1}{2}\left[X^{1}(3)+X^{1}(2)\right], 1 \\
-\frac{1}{2}\left[X^{1}(3)+X^{1}(4)\right], 1 \\
-\frac{1}{2}\left[X^{1}(4)+X^{1}(5)\right], 1
\end{array}\right]=\left[\begin{array}{l}
-104,1 \\
-167,1 \\
-253,1 \\
-332,1
\end{array}\right] \\
& y=\left(x^{0}(2), x^{0}(3), x^{0}(4), x^{0}(5)\right)^{T}=(7,2,74,78) 80^{T}
\end{aligned}
$$

Then obtain: $\mathrm{H}=\left(\begin{array}{l}\eta \\ \mathrm{h}\end{array}\right)=\left(B^{T} B\right)^{-1} B^{T} y=\left(\begin{array}{c}-0.0364 \\ 68.2035\end{array}\right)$, so $\eta=-0.0364, \mathrm{~h}=68.2035$,put $\quad X^{0}(1)=68 \quad(\mathrm{k}=5)$

$$
X^{1}(k+1)=\left[X^{(0)}-\frac{h}{\eta}\right] e^{-k \eta}+\frac{h}{\eta}
$$

receive: $X^{1}(6)=455.6396$,doing the degradation and concluding:

$$
X^{0}(6)=\left(X^{1} 6\right)-X^{1} 5=455.6396-372=83.6396
$$

Finally, there is a precision test:

$$
\mathrm{e}(1)=0, \mathrm{e}(2)=0.0158, \mathrm{e}(3)=0.6393, \mathrm{e}(4)=0.0644, \mathrm{e}(5)=0.3623
$$

$\operatorname{so,\operatorname {min}}\{\Delta \mathrm{e}(\mathrm{k})\}=0, \max \{\Delta \mathrm{e}(\mathrm{k})\}=0.6393$.

$$
\begin{gathered}
\xi(1)=1, \xi(2)=0.9530, \quad \xi(3)=0.3333, \quad \xi(4)=0.8322, \quad \xi(5)=0.4687 \\
r_{1}=\frac{1}{n} \sum_{k=1}^{n} \xi_{1}(k)=\frac{1}{5}(1+0.9530+0.3333+0.8322+0.4687)=0.7175>0.6
\end{gathered}
$$

because, $\mathrm{r}_{1}=0.7175>0.6$, So pass. The $\mathrm{e}(\mathrm{k})$ is calculated from the above formula.

$$
e(k)=\left|x^{0}(k)-x_{*}^{0}(k)\right|=(0,0.0158,0.6393,0.0644)=0.3623<\mathrm{S}_{0}
$$

Therefore, the accuracy level is first level,C $<0.35$.

Finally, a posteriori difference test is adopted.In the emergency state, the total demand for emergency supplies is $(84+60=144)$ boxes.

\section{Conclusions}

Through the example analysis, it is will divide into push forecast and pull forecast for procession of urban emergency material demand forecasting. Because through the push model t, it not only can solve emergency supplies of emergency demand point, but also effectively reduce disaster losses. Through pull model, the accuracy of prediction can improve. The dynamic model and algorithm presented in this text can meet the requirements of real-time continuity and dynamic decision-making of emergency materials after unexpected incidents. 


\section{Acknowledgements}

This work was financially supported by Shenyang Program for Tackling Key Problems in Science and Technology (F15-126-9-00).

\section{References}

1. C. $W u$, Study on construction of urban emergency logistics system, Shandong University, 2013, 4-10.

2. F.Ordonez, P. Murali, M. M.Dessouky, Facility Location under Demand Uncertainty: Response to a Large-scale DBo-terror attack ,Socio-Economic Planning Sciences, 2012, 46(1):78-87.

3. H. Qiao,Study on demand classification and demand of emergency materials ,Beijing Jiaotong University, 2009.

4. X. Wang, Y. Zhuang, Case based reasoning for resource demand forecasting of unconventional emergencies , East China economic management, 2011, 01:115-117. 